\title{
Atividade Microbiana Cecal e Contribuição Nutricional da Cecotrofia em Coelhos Alimentados com Rações Contendo Diferentes Fontes de Fibra e Níveis de Amido ${ }^{1}$
}

\author{
Alex Martins Varela de Arruda ${ }^{2}$, Darci Clementino Lopes ${ }^{3}$, Walter Motta Ferreira ${ }^{4}$, Horacio \\ Santiago Rostagno ${ }^{3}$, Augusto Cesar de Queiroz ${ }^{3}$, Elzânia Sales Pereira ${ }^{2}$, José Francisco da \\ Silva $^{3}$, Gulab Newandram Jham $^{5}$
}

\begin{abstract}
RESUMO - Objetivou-se neste estudo a avaliação da atividade microbiana cecal e a contribuição nutricional da cecotrofia em coelhos alimentados com rações contendo diferentes níveis de amido ( 22 a 32\% em média) mediante a inclusão de milho grão e diferentes fontes de fibra (feno de alfafa ou casca de soja), em esquema fatorial $2 \times 2$. No primeiro experimento, 40 coelhos alojados em gaiolas de engorda individuais, em delineamento inteiramente casualizado e alimentados à vontade dos 45 aos 85 dias de idade, foram abatidos para coleta dos conteúdos ileais e cecais. A concentração de ácidos graxos voláteis foi influenciada pela interação entre tratamentos, sendo $93,82 \mathrm{mmol} /$ 1 para ração de maior nível de amido com casca de soja e $80,03 \mathrm{mmol} / 1$ para ração de menor nível de amido com feno de alfafa. No segundo experimento, 40 coelhos aos 65 dias de idade, alojados em gaiolas de engorda individuais, em delineamento inteiramente casualizado, foram alimentados à vontade por 10 dias, e receberam colares de madeira para permitir a coleta total de cecotrofos. Houve influência da interação entre tratamentos sobre os teores de proteína e energia dos cecotrofos, sendo de $29,66 \%$ e 4204,87 kcal $/ \mathrm{kg}$ para ração contendo maiores níveis de amido e casca de soja e de $27,98 \%$ e $4080,46 \mathrm{kcal} / \mathrm{kg}$ para ração contendo menores níveis de amido e feno de alfafa. As rações de alto amido ou com casca de soja propiciaram maior enriquecimento do conteúdo cecal e melhor aporte nutricional para os coelhos.
\end{abstract}

Palavras-chave: casca de soja, cecotrofia, coelhos, feno de alfafa, microflora cecal, milho

\section{Caecal Microbial Activity and Caecotrophy Nutritional Contribution in Rabbits Fed Diets with Different Starch Levels and Fiber Sources}

\begin{abstract}
The objective of this study was to evaluate the caecal microbial activity and caecotrophy nutritional contribution in rabbits fed diets with differents starch levels (22 or 32\% on average) from a high or low inclusion of corn grain and differents fiber sources (alfalfa hay or soybean hulls), in a 2x2 factorial design. In the first experiment, 40 rabbits were individually housed in fattening cages within entirely randomized design, and fed ad libitum from 45 to 85 days of age, when they were slaughtered for collection of the ileal and caecal contents. The VFA total concentration was influenced by the interaction among treatments, being $93.82 \mathrm{mmol} / 1$ for the diets with high starch level and soybean hulls and $80.03 \mathrm{mmol} / \mathrm{l}$ for the diets with low starch level and alfalfa hay. In the second experiment, 40 rabbits aged 65 days were housed individually in fattening cages, in a completly randomized design, fed ad libitum for 10 days, and then received a wood necklace to allow caecotrophes collection. There was influence of the interaction between treatments on the caecotrophes protein and energy levels, being $29.66 \%$ and $4204.87 \mathrm{kcal} / \mathrm{kg}$ for the diets with high starch level and soybean hulls, and $27.98 \%$ and $4080.46 \mathrm{kcal} / \mathrm{kg}$ for the diets with low starch level and alfalfa hay. The diets with high starch level and those with soybean hulls showed higher enrichment of caecal contents and the best nutritional support for the rabbits.
\end{abstract}

Key Words: alfalfa hay, caecal microorganisms, caecotrophagy, corn, rabbits, soybean hulls

\section{Introdução}

O estudo de alimentos fibrosos alternativos na alimentação de coelhos visa reduzir os custos de produção, devido à habilidade destes animais em extrair nutrientes a partir de alimentos nãoconvencionais e transformá-los em carne de alto valor biológico para nutrição humana. Neste sentido, pode-se hipotizar sobre a possibilidade em diminuir o uso de grãos na nutrição cunícola, reduzindo a competição com outras espécies não-ruminantes e evitando distúrbios nutricionais relacionados ao excesso de cereais na dieta destes animais.

De acordo com Cheeke \& Patton (1980) e Gidenne (1995a), aumento no teor de amido da dieta pela inclusão excessiva de cereais, especialmente o milho, pode provocar alterações no processo digestivo dos coelhos, ao modificar a produção dos ácidos graxos

\footnotetext{
1 Parte da Tese de Doutorado do primeiro autor, financiado pela UFV e FAPEMIG.

2 Professor do curso de Zootecnia da UNIOESTE, Mal. Cândido Rondon - PR. E.mail: amvarela@unioeste.br

3 Professor do curso de Zootecnia da UFV, Viçosa - MG.

4 Professor do curso de Veterinária da UFMG, Belo Horizonte - MG.

5 Professor do curso de Química da UFV, Viçosa - MG.
} 
voláteis no ceco, causando desidratação por mudanças na pressão osmótica intestinal, disbioses microbianas e altas taxas de mortalidade na fase de crescimento. Dessa forma, a teoria da sobrecarga de amido no ceco dos coelhos refere-se a mudanças no padrão fermentativo cecal e ao desenvolvimento de uma população microbiana subdominante, especialmente colibacilos e clostridios gerando diarréias e enterotoxemias (Morisse, 1986; De Blas, 1991; Peeters et al., 1995).

De acordo com Ferreira (1989), um nível mínimo de alimentos fibrosos e inclusão máxima de cereais são permissíveis, diferenciando esta espécie com relação ao balanceamento dietético eà eficiência no aproveitamento da energia. Muitas pesquisas têm procurado avaliar a substituição do amido por fibra digestível suplementada com óleos, em rações para coelhos em crescimento, visando manter bons índices produtivos e a sanidade do plantel, especialmente láparos após a desmama (Lebas, 1999; Carabaño, 2000).

Assim, espécies herbívoras não-ruminantes de ceco funcional, como os coelhos, possuem a característica de acomodar em seu trato digestivo uma população microbiana simbiótica, com funções digestivas nas quais o hospedeiro é incapaz de realizar, como a digestão de carboidratos estruturais, a síntese de aminoácidos essenciais e de vitaminas do complexo $\mathrm{B}$, permitindo a sobrevivência à base de rações de baixo valor nutricional como os alimentos fibrosos (Cheeke, 1987; De Blas, 1989).

Os ácidos orgânicos são absorvidos pela parede intestinal e pelo consumo do conteúdo cecal na forma de cecotrofos, juntamente com os corpos bacterianos e seus produtos metabólicos, denominando-se cecotrofia - adaptação anatomo-fisiológica de natureza evolucionária, onde, a cada intervalo de tempo transcorrido do consumo de alimento, ocorre uma contração cecal, expelindo seu conteúdo através do cólon e reto, sendo consumindo diretamente da região anal (Lleonart, 1980; Lang, 1981). A eficiência digestiva nos coelhos relaciona-se com a cecotrofia, ingestão de cecotrofos ou fezes moles, cuja constituição difere das fezes duras ou verdadeiras, em termos de composição, tamanho e processo de formação, pois os mecanismos peristálticos, a absorção e liberação de água, eletrólitos, amônia e ácidos graxos volátes são distintas para esta dualidade, apresentando inter-relações complexas entre o metabolismo bacteriano e ciclo de excreção fecal ao longo do intestino grosso (Proto, 1976; Vernay, 1987).
Portanto, os coelhos estão adaptados ao consumo de alimentos fibrosos, especialmente pelo fato de os constituintes menos digestíveis da parede celular concorrerem para manutenção do funcionamento normal do sistema digestivo. Assim, o presente estudo objetivou avaliar a influência de diferentes fontes de fibra e níveis de amido, em rações para coelhos da raça Nova Zelândia Branco, sobre a atividade microbiana cecal e contribuição nutricional da cecotrofia durante a fase de crescimento.

\section{Material e Métodos}

Dois experimentos foram conduzidos no setor de Cunicultura, do Departamento de Zootecnia, do Centro de Ciências Agrárias, da Universidade Federal de Viçosa.

Com relação às instalações, os animais foram alojados em gaiolas individuais de arame galvanizado, com dimensões de $40 \mathrm{~cm}$ x $60 \mathrm{~cm} \times 45 \mathrm{~cm}$ (comprimento, largura e altura), providas de bebedouros automáticos tipo chupeta e comedouro de chapa galvanizada semi-automático, instalados em um galpão de alvenaria com 6 metros de largura, pédireito de 3 metros, cobertura de telha de amianto e muretas laterais providas de tela e cortinas de plástico para controle da ventilação. Diariamente, registrouse a temperatura por meio de um termômetro de máxima e mínima, instalado à altura da gaiolas, sendo de 31 e $19^{\circ} \mathrm{C}$ a amplitude térmica média durante o período experimental.

Em ambos os experimentos, coelhos machos e fêmeas em igual proporção foram distribuídos em um delineamento experimental inteiramente casualizado, em esquema fatorial $(2 \times 2)$ constituindo quatro tratamentos dietéticos, resultantes de dois níveis de amido a partir da inclusão de milho grão (22 e 32\% de amido em média) e duas fontes de fibra (feno de alfafa ou casca de soja), ambas associadas com sabugo de milho. As amostras do alimento e das rações foram coletadas, processadas em moinho tipo Wiley, peneira de malha $1,0 \mathrm{~mm}$, e em seguida acondicionadas em recipientes plásticos identificados para as análises de matéria seca, matéria mineral, extrato etéreo, proteína bruta, energia bruta, amido (hidrólise enzimática), fibra em detergente neutro, fibra em detergente ácido e lignina, realizadas no Laboratório de Nutrição Animal, no Departamento de Zootecnia da Universidade Federal de Viçosa, conforme metodologia e técnicas descritas pela 
AOAC (1990), Silva (1990) e Van Soest et al. (1991).

As rações experimentais foram formuladas levando-se em consideração as exigências nutricionais dos coelhos em fase de crescimento, conforme as recomendações do NRC (1977), INRA (1984) e Lebas et al. (1986), sendo posteriormente peletizadas. As composições percentual e química dos tratamentos dietéticos encontram-se nas Tabelas 1 e 2, respectivamente.

No primeiro experimento, para avaliar a influência das fontes de fibra e níveis de amido dietéticos sobre a atividade microbiana cecal, foram utilizados 40 animais, desmamados aos 35 dias, totalizando 10 repetições por tratamento, alojados individualmente e distribuídos aleatoriamente aos tratamentos, e alimentados com as rações experimentais por um período de 50 dias (similar ao ensaio de desempenho ou engorda realizado paralelamente), no qual receberam água e alimento à vontade. Ao final deste período, os coelhos foram abatidos por atordoamento e sangria na jugular, em torno das 18:00 h, visando separar o efeito dos tratamentos do ritmo circadiano de cecotrofia (produção e metabolismo de ácidos graxos voláteis no ceco), procedendo-se à pesagem dos compartimentos digestivos, retirada do conteúdo cecal, pesagem, homogeneização e mensuração do pH (Ferreira et al., 1996), além da pesagem da porção ileal do intestino delgado e coleta da digesta do íleo para análise do conteúdo de matéria seca e amido.

Para a análise da amônia $\left(\mathrm{NH}_{3}\right)$ e dos ácidos graxos voláteis (AGV), parte do material homogeneizado, cerca de $20 \mathrm{~g}$ de digesta, foi misturada com igual volume de água destilada e centrifugada por 20 minutos a $10.000 \mathrm{rpm}$, sendo a fração sobrenadante filtrada e separada em dois frascos distintos. Em um frasco adicionou-se volume igual ao pipetado de ácido clorídrico $0,2 \mathrm{~N}$, para atuar como conservante e evitar perdas de nitrogênio, destinandose estas amostras à análise de $\mathrm{NH}_{3}$. Ao outro frasco, adicionou-se uma solução de ácido metafosfórico a $20 \%(0,1 \mathrm{~mL}$ para cada $1,0 \mathrm{~mL}$ do líquido obtido), para conservar as amostras, evitar atividade fermentativa e contaminações, destinando-se estas amostras à análise de AGV. Todos estas amostras e o restante do material cecal foram identificados e armazenados em freezer $\left(-10^{\circ} \mathrm{C}\right)$ para posteriores análises químicas (Arruda, 1997; Gomes, 1996).

$\mathrm{O} \mathrm{pH}$ da digesta cecal foi determinado no momento da coleta, por intermédio de potenciômetro; a concentração de amônia, com tetraborato de sódio a
$25 \%$ para destilação e recolhimento em ácido bórico para titulação com $\mathrm{HCl}$ a $0,01 \mathrm{~N}$; e a concentração dos AGV nas amostras do ceco, por meio de cromatografia-gasosa, em que os padrões cromatográficos utilizados constituíram-se de ácido acético, ácido propiônico, ácido butírico e ácido valérico, conforme a metodologia e técnicas utilizadas por Ferreira et al. (1996), Gomes (1996), Arruda (1997), sendo estas efetuadas no Departamento de Química da Universidade Federal de Viçosa.

No segundo experimento, para avaliar a influência das fontes de fibra e dos níveis de amido sobre a composição e produção dos cecotrofos e a contribuição nutricional dos cecotrofos em relação aos nutrientes ingeridos com as rações experimentais, foram utilizados 40 coelhos aos 65 dias de idade, totalizando 10 repetições por tratamento, alimentados com ração comercial durante a fase de crescimento, selecionados e uniformizados com base no peso vivo e, posteriormente, distribuídos aleatoriamente aos tratamentos, como no primeiro ensaio. O período préexperimental teve duração de 10 dias, sendo no último dia feita a adaptação ao colar, seguindo-se o período experimental com duração de 48 horas, em que o fornecimento de alimento e água foi à vontade, e a coleta total dos cecotrofos.

Os animais foram alojados individualmente em gaiolas de engorda adaptadas com uma tela coletora para recolhimento de fezes e cecotrofos, similares às gaiolas de metabolismo idealizadas por Carregal (1976). Cada coelho recebeu um colar de madeira circular medindo $25 \mathrm{~cm}$ de diâmetro e com um orifício interno central de $7 \mathrm{~cm}$, similares aos idealizados por Ferreira et al. (1996). Durante o período de coleta, o consumo de ração foi mensurado e o recolhimento dos cecotrofos e das fezes foi efetuado de 2 em 2 horas, sendo pesados, identificados e acondicionados em freezer a $-10^{\circ} \mathrm{C}$ para posteriores análises químicas. As amostras do alimento, das fezes e dos cecotrofos foram processadas em moinho tipo wiley, peneira de malha $1,0 \mathrm{~mm}$ e, em seguida, acondicionadas em recipientes apropriados e identificados, para as análises químicas citadas anteriormente, conforme metodologia e técnicas descritas pela AOAC (1990), Silva (1990) e Van Soest et al. (1991), realizadas no Laboratório de Nutrição Animal, no Departamento de Zootecnia, da Universidade Federal de Viçosa.

Em ambos os ensaios, tanto para atividade microbiana cecal quanto para contribuição nutricional da cecotrofia, os dados experimentais foram 
submetidos à análise de variância e teste de médias a 5\% de significância (Student Newman Keulls) contidos no programa SAEG - Sistema de Análises Estatísticas e Genéticas (UFV, 1997). O modelo estatístico para avaliação da atividade microbiana cecal e contribuição nutricional da cecotrofia foi :

$$
Y_{i j k}=m+A_{i}+F_{j}+A F_{i j}+e_{i j k}
$$

em que $\mathrm{Y}_{\mathrm{ijkl}}=$ valor observado das variáveis estudadas, relativo a cada unidade experimental 1 , que recebeu a ração com nível de amido i e fonte de fibra $\mathrm{j} ; \mathrm{m}=$ média geral da característica; $\mathrm{A}_{\mathrm{i}}=$ efeito do nível de amido $(i=1$ e 2$) ; F_{j}=$ efeito da fonte de fibra $(\mathrm{j}=1$ e 2$) ; \mathrm{AF}_{\mathrm{ij}}=$ efeito da interação nível de amido $\mathrm{i}$ e fonte de fibra $\mathrm{j}$; e $\mathrm{E}_{\mathrm{ijkl}}=$ erro aleatório associado a cada observação.

Tabela 1 - Composição percentual das rações experimentais

Table 1 - Composition of the experimental diets (\%)

\begin{tabular}{|c|c|c|c|c|}
\hline \multirow[t]{2}{*}{$\begin{array}{l}\text { Ingredientes } \\
\text { Ingredients }\end{array}$} & \multicolumn{4}{|c|}{$\begin{array}{l}\text { Tratamentos dietéticos } \\
\text { Dietary treatments }\end{array}$} \\
\hline & $\begin{array}{c}\text { Alto amido c/ feno } \\
\text { de alfafa AAFA } \\
\text { High starch, } \\
\text { alfalfa hay }\end{array}$ & $\begin{array}{c}\text { Alto amido c/ casca } \\
\text { de soja AACS } \\
\text { High starch, } \\
\text { soybean hulls }\end{array}$ & $\begin{array}{c}\text { Baixo amido c/ feno } \\
\text { de alfafa BAFA } \\
\text { Low starch, } \\
\text { alfalfa hay }\end{array}$ & $\begin{array}{c}\text { Baixo amido c/ casca } \\
\text { de soja BACS } \\
\text { Low starch, } \\
\text { soybean hulls }\end{array}$ \\
\hline $\begin{array}{l}\text { Milho grão moído } \\
\text { Ground corn grain }\end{array}$ & 46,0 & 47,5 & 28,0 & 30,0 \\
\hline $\begin{array}{l}\text { Feno de alfafa } \\
\text { Alfalfa hay }\end{array}$ & 20,0 & - & 35,0 & - \\
\hline $\begin{array}{l}\text { Casca de soja } \\
\text { Soybean hulls }\end{array}$ & - & 15,0 & - & 25,0 \\
\hline $\begin{array}{l}\text { Óleo de soja } \\
\text { Soybean oil }\end{array}$ & - & - & 4,60 & 5,00 \\
\hline $\begin{array}{l}\text { Farelo de soja } \\
\text { Soybean meal }\end{array}$ & 16,0 & 20,0 & 13,5 & 20,7 \\
\hline $\begin{array}{l}\text { Farelo de trigo } \\
\text { Wheat bran }\end{array}$ & 9,00 & 9,00 & 9,00 & 9,00 \\
\hline $\begin{array}{l}\text { Sabugo milho } \\
\text { Ground corn cob }\end{array}$ & 6,00 & 5,00 & 6,00 & 5,00 \\
\hline $\begin{array}{l}\text { Sal comum } \\
\text { Salt }\end{array}$ & 0,60 & 0,60 & 0,60 & 0,60 \\
\hline $\begin{array}{l}\text { Calcário } \\
\text { Limestone }\end{array}$ & 0,60 & 1,10 & 0,05 & 0,85 \\
\hline $\begin{array}{l}\text { Fosfato bicálcico } \\
\text { Dicalcium phosphate }\end{array}$ & 1,00 & 0,90 & 1,20 & 1,10 \\
\hline $\begin{array}{l}\text { Suplem. Min. Vit.* } \\
\text { Mineral and vitamin premix }\end{array}$ & 0,40 & 0,40 & 0,40 & 0,40 \\
\hline $\begin{array}{l}\text { DL-metionina } \\
\text { DL-methionine }\end{array}$ & 0,05 & 0,05 & 0,10 & 0,10 \\
\hline $\begin{array}{l}\text { L-lisina } \\
\text { L-lysine }\end{array}$ & 0,10 & 0,04 & 0,09 & 0,02 \\
\hline $\begin{array}{l}\text { Caulim } \\
\text { Caulin }\end{array}$ & 0,25 & 0,41 & 1,46 & 2,23 \\
\hline Total (kg) & 100 & 100 & 100 & 100 \\
\hline
\end{tabular}


Tabela 2 - Composição química das rações experimentais (base da MS)

Table 2 - Chemical composition of experimental diets (dry matter basis)

\begin{tabular}{|c|c|c|c|c|}
\hline \multirow[t]{2}{*}{$\begin{array}{l}\text { Ingredientes } \\
\text { Ingredients }\end{array}$} & \multicolumn{4}{|c|}{$\begin{array}{l}\text { Tratamentos dietéticos } \\
\text { Dietary treatments }\end{array}$} \\
\hline & $\begin{array}{c}\text { Alto amido c/ feno } \\
\text { de alfafa AAFA } \\
\text { High starch, } \\
\text { alfalfa hay }\end{array}$ & $\begin{array}{c}\text { Alto amido c/ casca } \\
\text { de soja AACS } \\
\text { High starch, } \\
\text { soybean hulls }\end{array}$ & $\begin{array}{c}\text { Baixo amido c/ feno } \\
\text { de alfafa BAFA } \\
\text { Low starch, } \\
\text { alfalfa hay }\end{array}$ & $\begin{array}{c}\text { Baixo amido c/ casca } \\
\text { de soja BACS } \\
\text { Low starch, } \\
\text { soybean hulls }\end{array}$ \\
\hline $\begin{array}{l}\text { Amido }(\%) \\
\text { Starch }\end{array}$ & 31,91 & 32,81 & 21,57 & 22,68 \\
\hline $\begin{array}{l}\text { Fibra detergente neutro (\%) } \\
\text { Neutral detergent fiber }\end{array}$ & 24,47 & 23,23 & 30,31 & 28,92 \\
\hline $\begin{array}{l}\text { Fibra detergente ácido (\%) } \\
\text { Acid detergent fiber }\end{array}$ & 14,04 & 14,43 & 18,18 & 18,68 \\
\hline $\begin{array}{l}\text { Lignina }(\%) \\
\text { Lignin }\end{array}$ & 4,00 & 2,80 & 5,90 & 3,70 \\
\hline $\begin{array}{l}\text { Extrato etéreo (\%) } \\
\text { Ether extract }\end{array}$ & 3,11 & 2,90 & 7,41 & 7,40 \\
\hline $\begin{array}{l}\text { Energia bruta }(\mathrm{kcal} / \mathrm{kg}) \\
\text { Gross energy }\end{array}$ & 4415 & 4281 & 4708 & 4597 \\
\hline $\begin{array}{l}\text { Energia digestível* }(\mathrm{kcal} / \mathrm{kg}) \\
\text { Digestible energy }\end{array}$ & 2723 & 2764 & 2583 & 2627 \\
\hline $\begin{array}{l}\text { Proteína bruta (\%) } \\
\text { Crude protein }\end{array}$ & 17,07 & 17,10 & 17,12 & 17,09 \\
\hline $\begin{array}{l}\text { Proteína digestível } *(\%) \\
\text { Digestible protein }\end{array}$ & 12,08 & 12,36 & 10,89 & 11,27 \\
\hline $\begin{array}{l}\text { Relação kcal } \mathrm{ED} / \mathrm{gPD} \\
\text { Energy/protein digestible ratio* }\end{array}$ & 22,54 & 22,36 & 23,72 & 23,31 \\
\hline $\begin{array}{l}\text { Cálcio (\%) } \\
\text { Calcium }\end{array}$ & 0,80 & 0,79 & 0,80 & 0,79 \\
\hline $\begin{array}{l}\text { Fósforo total (\%) } \\
\text { Total phosphorus }\end{array}$ & 0,53 & 0,54 & 0,53 & 0,54 \\
\hline $\begin{array}{l}\text { Lisina } * *(\%) \\
\text { Lysine }\end{array}$ & 0,92 & 0,92 & 0,92 & 0,92 \\
\hline $\begin{array}{l}\text { Metionina ** }(\%) \\
\text { Methionine }\end{array}$ & 0,58 & 0,59 & 0,58 & 0,59 \\
\hline
\end{tabular}

* Determinado a partir dos resultados do ensaio de digestibilidade (Determined from results of digestibility assay).

** Calculado a partir dos valores nutricionais dos alimentos para coelhos obtidos pelo INRA (1984) (Calculated from the food nutritional values to rabbits obtained by INRA, 1984).

\section{Resultados e Discussão}

Os valores médios referentes à atividade microbiana cecal em coelhos alimentados com rações contendo diferentes níveis de amido e fontes de fibra são apresentados na Tabela 3 e aqueles referentes à cecotrofia, na Tabela 4 . Na análise de variância, os parâmetros que não demonstraram efeito significativo para interação entre nível de amido e fonte de fibra $(\mathrm{P}<0,05)$ tiveram as médias agrupadas para estes fatores isoladamente, porém aqueles que apresentaram significância estatística para a interação fibra e amido foram desdobrados em médias pertinentes aos tratamentos (Pimentel Gomes, 1987).

No primeiro experimento, o peso compartimento cecal intacto, peso do conteúdo cecal na matéria natural e peso do conteúdo cecal na matéria seca foram constatados efeitos significativos para nível de amido $(\mathrm{P}<0,05)$ e fonte de fibra $(\mathrm{P}<0,05)$, mas não para a interação entre eles. Na Tabela 3 , pode-se observar que os maiores pesos do ceco e do conteúdo cecal, observado nas rações com maiores níveis de amido (AA), possivelmente estejam relacionados com tempo de retenção da digesta, pois, mantendose constante o tamanho de partícula, menores níveis de fibra ou inferiores ao mínimo recomendado podem proporcionar aumento do peso do ceco ou do conteúdo cecal, em função do efeito regulatório dos componentes lignocelulósicos sobre o fluxo da digesta e dualidade na excreção fecal nestes compartimentos

R. Bras. Zootec., v.32, n.4, p.891-902, 2003 
Tabela 3 - Características do conteúdo cecal e ileal, e atividade microbiana cecal de coelhos Table 3 - Caecal and ileal contents characteristics, and caecal microbial activity with rabbits

\begin{tabular}{|c|c|c|c|c|c|c|}
\hline \multirow[b]{3}{*}{$\begin{array}{l}\text { Parâmetros } \\
\text { Parameters }\end{array}$} & \multicolumn{4}{|c|}{$\begin{array}{c}\text { Tratamentos } \\
\text { Treatments }\end{array}$} & \multirow{3}{*}{$\begin{array}{l}\text { Média } \\
\text { Mean }\end{array}$} & \multirow{3}{*}{$\mathrm{CV}(\%)$} \\
\hline & \multicolumn{2}{|c|}{$\begin{array}{l}\text { Nível de amido } \\
\text { Starch level }\end{array}$} & \multicolumn{2}{|c|}{$\begin{array}{l}\text { Fonte de fibra } \\
\text { Fiber source }\end{array}$} & & \\
\hline & AA 1,2 & $\mathrm{BA}^{3,4}$ & FA 1,3 & $\mathrm{CS}^{2,4}$ & & \\
\hline Peso ceco intacto $(\mathrm{g})$ & $159,25^{\mathrm{a}}$ & $139,00^{b}$ & $132,25^{\mathrm{f}}$ & $166,00^{\mathrm{e}}$ & 149,12 & 8,21 \\
\hline $\begin{array}{l}\text { Intact caecal weight } \\
\text { Peso cont. cecal }(\mathrm{g}) \\
\text { Caecal contents weight }\end{array}$ & $112,75^{\mathrm{a}}$ & $95,75^{\mathrm{b}}$ & $89,50^{f}$ & $119,00^{\mathrm{e}}$ & 104,25 & 8,64 \\
\hline $\begin{array}{l}\text { Peso cont. cecal MS }(\mathrm{g}) \\
\text { DM caecal contents weight }\end{array}$ & $33,34^{\mathrm{a}}$ & $26,52^{b}$ & $24,97^{\mathrm{f}}$ & $34,89^{\mathrm{e}}$ & 29,93 & 8,96 \\
\hline $\begin{array}{l}\text { Índice } \mathrm{pH} \text { cecal } \\
\text { Caecal } \mathrm{pH}\end{array}$ & $6,091^{a}$ & $6,097^{\mathrm{a}}$ & $6,108^{e}$ & $6,079^{f}$ & 6,09 & 0,72 \\
\hline $\begin{array}{l}\mathrm{NH}_{3} \text { cecal }(\mathrm{mg} / 100 \mathrm{~mL}) \\
\text { Caecal } \mathrm{NH}_{3}\end{array}$ & $7,25^{\mathrm{b}}$ & $7,65^{\mathrm{a}}$ & $7,56^{\mathrm{e}}$ & $7,33^{f}$ & 7,45 & 3,71 \\
\hline $\begin{array}{l}\text { Acetato }(\%) \\
\text { Acetic acid }\end{array}$ & $74,59^{b}$ & $79,76^{\mathrm{a}}$ & $77,33^{\mathrm{e}}$ & $77,02^{\mathrm{e}}$ & 77,17 & 1,06 \\
\hline Propionato (\%) & $9,15^{\mathrm{a}}$ & $7,14^{b}$ & $7,81^{\mathrm{f}}$ & $8,48^{e}$ & 8,14 & 4,01 \\
\hline $\begin{array}{l}\text { Propionic acid } \\
\text { Butirato }(\%)\end{array}$ & $15,33^{\mathrm{a}}$ & $12,53^{\mathrm{b}}$ & $14,15^{\mathrm{e}}$ & $13,71^{\mathrm{e}}$ & 13,93 & 5,27 \\
\hline $\begin{array}{l}\text { Butyric acid } \\
\text { Valerato }(\%) \\
\text { Valeric acid } \\
\text { Amido cont. ileal (\%) } \\
\text { Ileal starch content }\end{array}$ & $\begin{array}{l}0,91^{\mathrm{a}} \\
9,52^{\mathrm{a}}\end{array}$ & $\begin{array}{l}0,56^{\mathrm{b}} \\
6,81^{\mathrm{b}}\end{array}$ & $\begin{array}{l}0,70^{\mathrm{e}} \\
8,47^{\mathrm{e}}\end{array}$ & $\begin{array}{l}0,77^{\mathrm{e}} \\
7,86^{\mathrm{f}}\end{array}$ & $\begin{array}{l}0,74 \\
8,17\end{array}$ & $\begin{array}{r}16,9 \\
7,01\end{array}$ \\
\hline & & $\begin{array}{r}\text { Trat } \\
\operatorname{Tr} \\
\end{array}$ & $\begin{array}{l}\text { ntos } 6 \\
\text { ents }\end{array}$ & & $\begin{array}{l}\text { Média } \\
\text { Mean }\end{array}$ & $\mathrm{CV}(\%)$ \\
\hline $\begin{array}{l}\text { Parâmetros } \\
\text { Parameters }\end{array}$ & $\mathrm{AAFA}^{1}$ & $\mathrm{AACS}^{2}$ & $\mathrm{BAFA}^{3}$ & $\mathrm{BACS}^{4}$ & & \\
\hline $\begin{array}{l}\text { Matéria seca cecal (\%) } \\
\text { Caecal dry matter }\end{array}$ & $29,13^{\mathrm{ij}}$ & $29,92^{i}$ & $26,42^{\mathrm{k}}$ & $28,63^{j}$ & 28,53 & 3,29 \\
\hline $\begin{array}{l}\text { Conc. total AGV cecal }(\mathrm{mmol} / \mathrm{l}) \\
V F A \text { caecal concentration }\end{array}$ & $86,12^{\mathrm{k}}$ & $93,82^{\mathrm{i}}$ & $80,03^{1}$ & $90,55^{\mathrm{j}}$ & 87,53 & 1,90 \\
\hline $\begin{array}{l}\text { Matéria seca ileal }(\%) \\
\text { Ileal dry matter }\end{array}$ & $9,75^{\mathrm{i}}$ & $9,17^{\mathrm{i}}$ & $7,00^{\mathrm{j}}$ & $7,68^{\mathrm{j}}$ & 8,40 & 11,15 \\
\hline 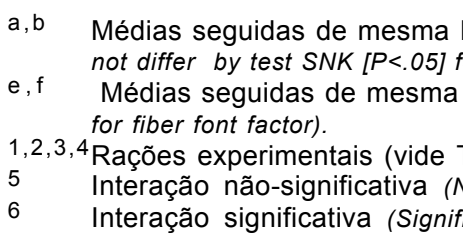 & $\begin{array}{l}\text { não diferen } \\
\text { arch level fac } \\
\text { a não difere } \\
\text { las } 1 \text { e 2) } \\
\text { ignificant int } \\
\text { interaction). }\end{array}$ & $\begin{array}{l}\text { teste SNK } \\
0,05) \text { para } \\
\text { mental diets } \\
\text { n). }\end{array}$ & $\begin{array}{l}\text {,05) para fa } \\
\text { fonte de fibr } \\
\text { Tables } 1 \text { and }\end{array}$ & $\begin{array}{l}\text { ível de amid } \\
\text { leans followec }\end{array}$ & ne letter do & $\begin{array}{l}\text { ame letter do } \\
\text { differ }[P<.05]\end{array}$ \\
\hline
\end{tabular}

digestivos (Cheeke, 1987; De Blas, 1989; Bellier \& Gidenne, 1996). Na Tabela 3, observa-se também que o maior peso do ceco e do conteúdo cecal, com as rações contendo casca de soja (CS), relaciona-se com a natureza química da parede celular dos alimentos fibrosos, pois, segundo Lebas (1991) e Gidenne (1996), mantendo-se constante o nível de fibra dietética, o maior desenvolvimento do ceco observado com fontes de fibra mais digestíveis devese a estímulos químicos mais intensos, como a elevação na concentração de ácidos graxos voláteis oriundos da ação microbiana, além de efeito físico relacionado a um fluxo e refluxo entre ceco e cólon dos coelhos, caracterizando hipomotilidade responsiva à hiperfermentação pela microbiota cecal (Lleonart, 1980; Lang, 1981; Peeters et al., 1995).

$\mathrm{O}$ índice $\mathrm{pH}$ cecal foi influenciado apenas pela fonte de fibra $(\mathrm{P}<0,05)$. Na Tabela 3, pode-se notar que o conteúdo cecal dos coelhos alimentados com as rações com casca de soja (CS) tiveram índice $\mathrm{pH}$ 
Tabela 4 - Composição e produção dos cecotrofos e contribuição nutricional da cecotrofia em porcentagem do consumo diário com coelhos

Table 4 - Composition and production of caecotrophes and caecotrophy nutritional contribution in percentage of daily feed intake in rabbits

\begin{tabular}{|c|c|c|c|c|c|c|}
\hline \multirow[b]{3}{*}{$\begin{array}{l}\text { Parâmetros } \\
\text { Parameters }\end{array}$} & \multicolumn{4}{|c|}{$\begin{array}{c}\text { Tratamentos } \\
\text { Treatments }\end{array}$} & \multirow{3}{*}{$\begin{array}{l}\text { Média } \\
\text { Mean }\end{array}$} & \multirow{3}{*}{ CV $(\%)$} \\
\hline & \multicolumn{2}{|c|}{$\begin{array}{c}\text { Nível de amido } \\
\text { Starch level } \\
\end{array}$} & \multicolumn{2}{|c|}{$\begin{array}{c}\text { Fonte de fibra } \\
\text { Fiber source } \\
\end{array}$} & & \\
\hline & AA 1,2 & $\mathrm{BA}^{3,4}$ & FA 1,3 & $\mathrm{CS}^{2,4}$ & & \\
\hline $\begin{array}{l}\text { Consumo de ração }(\mathrm{g} / \mathrm{d}) \\
\text { Feed intake }\end{array}$ & $80,00^{b}$ & $87,50^{\mathrm{a}}$ & $90,00^{\mathrm{e}}$ & $77,50^{\mathrm{b}}$ & 83,75 & 5,63 \\
\hline $\begin{array}{l}\text { Produção de cecotrofos } \\
\text { na matéria natural }(\mathrm{g} / \mathrm{d}) \\
\text { (caecotrophes production) }\end{array}$ & $46,50^{\mathrm{b}}$ & $53,50^{\mathrm{a}}$ & $55,00^{\mathrm{e}}$ & $45,00^{f}$ & 50,00 & 14,98 \\
\hline $\begin{array}{l}\text { Matéria seca }(\%) \\
\text { Dry matter }\end{array}$ & $36,81^{\mathrm{a}}$ & $33,37^{b}$ & $34,92^{\mathrm{f}}$ & $35,26^{\mathrm{e}}$ & 35,09 & 7,18 \\
\hline $\begin{array}{l}\text { Fibra det. neutro }(\%) \\
\text { Neutral detergent fiber }\end{array}$ & $19,75^{\mathrm{b}}$ & $28,36^{\mathrm{a}}$ & $24,77^{\mathrm{e}}$ & $23,34^{f}$ & 24,06 & 1,52 \\
\hline $\begin{array}{l}\text { Fibra det. ácido }(\%) \\
\text { Acid detergent fiber }\end{array}$ & $12,28^{\mathrm{b}}$ & $18,49^{\mathrm{a}}$ & $16,27^{\mathrm{e}}$ & $14,50^{\mathrm{f}}$ & 15,38 & 2,40 \\
\hline $\begin{array}{l}\text { Contribuição MS (\%) } \\
\text { DM contribution }\end{array}$ & $19,14^{\mathrm{a}}$ & $18,37^{b}$ & $19,21^{\mathrm{e}}$ & $18,29^{f}$ & 18,75 & 11,92 \\
\hline $\begin{array}{l}\text { Contribuição PB }(\%) \\
C P \text { contribution }\end{array}$ & $28,77^{\mathrm{a}}$ & $27,43^{\mathrm{a}}$ & $28,28^{\mathrm{e}}$ & $27,92^{\mathrm{e}}$ & 28,10 & 10,43 \\
\hline $\begin{array}{l}\text { Contribuição EB }(\%) \\
\text { GE contribution }\end{array}$ & $18,74^{\mathrm{a}}$ & $16,88^{b}$ & $17,92^{\mathrm{e}}$ & $17,70^{\mathrm{e}}$ & 17,81 & 12,09 \\
\hline $\begin{array}{l}\text { Contribuição FDN (\%) } \\
\text { NDF contribution }\end{array}$ & $12,64^{b}$ & $21,20^{\mathrm{a}}$ & $17,58^{e}$ & $16,25^{\mathrm{e}}$ & 16,91 & 12,27 \\
\hline $\begin{array}{l}\text { Contribuição FDA (\%) } \\
\text { ADF contribution }\end{array}$ & $11,94^{\mathrm{b}}$ & $20,00^{\mathrm{a}}$ & $16,94^{\mathrm{e}}$ & $14,99^{\mathrm{f}}$ & 15,97 & 12,63 \\
\hline & & $\begin{array}{r}\text { Trat } \\
\operatorname{Tr} \\
\end{array}$ & nents 6 & & $\begin{array}{l}\text { Média } \\
\text { Mean }\end{array}$ & CV $(\%)$ \\
\hline $\begin{array}{l}\text { Parâmetros } \\
\text { Parameters }\end{array}$ & $\mathrm{AAFA}^{1}$ & $\mathrm{AACS}^{2}$ & $\mathrm{BAFA}^{3}$ & $\mathrm{BACS}^{4}$ & & \\
\hline Proteína bruta (\%) & $28,84^{\mathrm{j}}$ & $29,66^{\mathrm{i}}$ & $27,98^{\mathrm{k}}$ & $29,61^{\mathrm{i}}$ & 29,03 & 1,01 \\
\hline $\begin{array}{l}\text { Crude protein } \\
\text { Energia bruta }(\mathrm{kcal} / \mathrm{kg}) \\
\text { Crude energy }\end{array}$ & $4168,26^{\mathrm{k}}$ & $4204,87^{i}$ & $4080,46^{1}$ & $4187,9^{1 \mathrm{j}}$ & 4160,37 & 1,73 \\
\hline 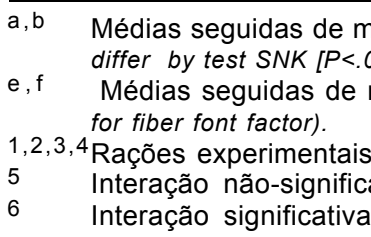 & $\begin{array}{l}\text { não diferem } \\
\text { level factor) } \\
\text { a não difere } \\
\text { las } 1 \text { e } 2 \text { ) } \\
\text { significant in } \\
t \text { interaction) }\end{array}$ & $\begin{array}{l}\text { teste SNK } \\
0,05) \text { para } \\
\text { imental diets } \\
\text { n). }\end{array}$ & $\begin{array}{l}\text { 05) para fatc } \\
\text { fonte de fib } \\
\text { Tables } 1 \text { ano }\end{array}$ & $\begin{array}{l}\text { vel de amido } \\
\text { Means followe }\end{array}$ & $\begin{array}{l}\text { ans followed } b \\
\text { same letter } d\end{array}$ & e letter do not \\
\hline
\end{tabular}

levemente menor que as rações com feno de alfafa (FA), possivelmente, relacionado à intensidade fermentativa propiciada a partir de cada fonte fibrosa adicionada às rações, visto que o aumento na concentração de ácidos graxos voláteis contribui para maior acidez cecal (Garcia et al., 1993; Peeters et al., 1995; Jehl \& Gidenne, 1996). Por outro lado, a variação quantitativa no teor de amido das rações foi suficiente para alteração mínima no índice $\mathrm{pH}$ do conteúdo cecal dos coelhos, pois os valores médios foram muito próximos, o que também foi verificado por Parigi-Bini et al. (1990) e Peeters et al. (1993). Isto se deve a grande variabilidade nos resultados de pesquisa, sugerindo-se que um efeito compensatório na secreção de tamponantes endógenos pode levar a discordâncias, quando da interpretação desta característica (Gidenne et al., 1991; Tortuero et al., 1994; Bellier \& Gidenne, 1996).

Os níveis de nitrogênio amoniacal no conteúdo cecal $\left(\mathrm{NNH}_{3}\right)$ dos coelhos foram influenciados 
$(\mathrm{P}<0,05)$ pelo nível de amido ou pela fonte de fibra das rações experimentais. Na Tabela 3, pode-se observar que as maiores concentrações de $\mathrm{NNH}_{3}$ cecal foram obtidas com as rações de baixo amido (BA), sugerindo que o aumento no teor de lignocelulose da dieta pode ter aumentado o metabolismo nitrogenado no ceco, em virtude de maior fluxo de nitrogênio e melhor sincronização com hidrocarbonetos fermentáveis que escaparam da ação enzimática no intestino delgado (Morisse, 1982; Morisse, 1986; Gidenne, 1995b; Bellier \& Gidenne, 1996). Com relação à fonte de fibra, as maiores concentrações de $\mathrm{NNH}_{3}$ observadas com as rações que continham feno de alfafa (FA) sugerem que, possivelmente, a maior lignificação da parede celular e o maior conteúdo de nitrogênio complexado a esta fonte fibrosa tenham alterado o metabolismo nitrogenado (Fraga et al., 1991), possivelmente pela maior entrada de nitrogênio endógeno e dietético no ceco (Carabaño et.al., 1989; Gidenne, 1996; Jehl \& Gidenne, 1996), já que a amônia é produto do metabolismo proteolítico e ureolítico cecal, usada na síntese de proteína microbiana, oriundas da uréia sangüínea e nitrogênio endógeno e dietético (Forsythe \& Parker, 1985 a,b; Makar \& Singh, 1987).

A concentração total de AGV sofreu influência da interação entre fonte de fibra e nível de amido $(\mathrm{P}<0,05)$. Na Tabela 3, pode-se verificar que as maiores concentrações foram mensuradas no conteúdo cecal dos coelhos alimentados com a ração de maior nível de amido e casca de soja (AACS), observando-se as menores concentrações na ração de menor nível amido e feno de alfafa (BAFA). Estes resultados sugerem que a natureza da fibra exerce influência significativa sobre a fermentação cecal, ao condicionar a qualidade do substrato que chega ao ceco para atividade fermentativa e o tempo de retenção para maior intensidade da mesma, paradoxalmente ao fato que componentes fenólicos da lignina possuem efeitos similares à antibióticos (Tortuero et al., 1994; Gidenne \& Jehl, 1996; Jehl \& Gidenne, 1996). O nível de amido, que neste estudo possuiu relação inversa ao nível de fibra dietético, também contribuiu para o efeito responsivo observado sobre a concentração total de AGV no ceco dos coelhos, reforçando o conceito de que rações com maiores níveis de amido enriquecem a composição da digesta cecal, proporcionando maior disponibilidade de energia para a atividade fermentativa dos microorganismos cecais (Carabaño et al., 1988;
Gidenne, 1995b; Arruda et al., 2000). Estes resultados sugerem que variações na atividade fermentativa microbiana, em função da relação amido/fibra da dieta, deva-se à influência sobre o tempo de passagem da digesta e tipo de substrato para degradabilidade cecal (Blas et al., 1990; Castrovilli \& Greppi, 1990), além da qualidade da fibra, visto que volumosos de alta digestibilidade tendem a proporcionar efeito similar ao de altos níveis de amido dietético (Peeters et al., 1995; Jehl \& Gidenne, 1996; Garcia et al., 1997). A microflora cecal produz AGV's (acético, propiônico e butírico), que são absorvidos por difusão e usados como fonte de energia, pela própria mucosa intestinal e metabolização hepática (Marty \& Vernay, 1984; Vernay, 1987), contribuindo em 33\% da energia digestível ingerida ou $50 \%$ da energia diária de mantença (Gidenne, 1995a,b).

A proporção molar dos AGV no conteúdo cecal dos coelhos não apresentou efeito da interação entre os fatores dietéticos, porém, verificou-se influência do nível de amido para ácido acético, ácido butírico, ácido valérico e traços de outros ácidos orgânicos $(\mathrm{P}<0,05)$, e influência da fonte de fibra ou do nível de amido para ácido propiônico $(\mathrm{P}<0,05)$. O ácido acético é predominante na fermentação da fibra, justificando os resultados obtidos, pois as rações de menor nível de amido (BA) propiciaram as maiores proporções molares de acetato no conteúdo cecal dos coelhos (Gidenne et al., 1991; Gidenne, 1995 a,b; Bellier \& Gidenne, 1996). A proporção molar entre o ácido propiônico e ácido butírico é inversa em relação ao padrão fermentativo encontrado em ruminantes e outros monogástricos de ceco funcional, devido ao perfil da microbiota e normalmente condicionado pela pequena quantidade de hidratos de carbono facilmente fermentáveis que chega ao ceco (Cheeke, 1987; De Blas, 1989; Gidenne, 1995b), justificando as maiores proporções molares de propionato e butirato no ceco de coelhos alimentados com as rações de maior nível de amido (AA). Isto possivelmente se deva ao fato de a concentração de amido ileal ter sido influenciada pelo nível de amido dietético $(\mathrm{P}<0,05)$, sendo maior para estes tratamentos (Tabela 3), o que também foi verificado por Gidenne \& Perez (1993 a,b) e Bellier \& Gidenne (1996).

Apesar de não constatar diferença entre as médias, uma leve superioridade na proporção molar de ácido butírico foi obtida com coelhos alimentados com rações contendo feno de alfafa (FA), possivelmente, associada à maior concentração de amido ileal que

\footnotetext{
R. Bras. Zootec., v.32, n.4, p.891-902, 2003
} 
alcançou o ceco, visto que a análise de variância foi significativa para fonte de fibra $(\mathrm{P}<0,05)$, e provavelmente, estas rações tenham reduzido indiretamente a digestibilidade do amido no intestino delgado (Cheeke, 1995; De Blas \& Wiseman, 1998). A proporção molar de ácido valérico compreende também traços de outros ácidos orgânicos, em virtude de sua pequena contribuição e para facilitar a discussão dos resultados, pois não permite inferências conclusivas (Church, 1988; Gidenne, 1996). Na Tabela 3 , pode-se notar que a elevação na proporção destes tende a acompanhar a maior proporção molar de ácido propiônico e butírico no conteúdo cecal de coelhos alimentados com as rações de maior nível de amido (AA), permitindo sugerir que o padrão fermentativo está altamente relacionado ao tipo de substrato, à motilidade do ceco-cólon e às características da microbiota cecal dos coelhos, destacando-se bacilos anaeróbicos não-esporulados gram-negativos, especialmente Bacteroides spp (Comi \& Cantoni, 1984; Pacini et al., 1986; Tortuero et al., 1994; Gidenne, 1996).

Com relação ao segundo experimento, o consumo de ração e a produção de cecotrofos foram influenciados $(\mathrm{P}<0,05)$ pelo nível de amido ou fonte de fibra, mas não para a interação. Na Tabela 4, pode-se observar que houve uma relação proporcional e direta entre a quantidade de ração consumida e quantidade de cecotrofos excretada pelos coelhos, em concordância com Bellier \& Gidenne (1996), sendo que os maiores valores foram obtidos com as rações de maior nível de amido (AA) e aquelas contendo feno de alfafa (FA). Isto sugere que os coelhos tendem a tirar melhor proveito da cecotrofia, quando há maior atividade fermentativa ou presença de volumoso com fibra de menor digestibilidade na dieta, pelos efeitos fisiológicos proporcionados por estes fatores alimentares intrínsecos, como a maior taxa de renovação do conteúdo cecal (Proto, 1976; Proto, 1984; Santomá et al., 1993; Jehl \& Gidenne, 1996).

Sobre a composição química dos cecotrofos, houve influência do nível de amido $(\mathrm{P}<0,05)$ sobre os teores de matéria seca, fibra em detergente neutro e fibra em detergente ácido dos cecotrofos. Também se verificou influência da fonte de fibra $(\mathrm{P}<0,05)$ sobre os teores de matéria seca, fibra em detergente neutro e fibra em detergente ácido dos cecotrofos. Por outro lado, houve efeito da interação entre nível de amido e fonte de fibra $(\mathrm{P}<0,05)$ sobre os teores de proteína e energia dos cecotrofos dos coelhos alimentados com as rações experimentais. Os valores médios da composição química dos cecotrofos apresentados na Tabela 4 permitem sugerir que as variações observadas entre as médias de matéria seca, possivelmente, devam-se à inter-relação entre o tipo de substrato e o complexo mecanismo de secreção e absorção de tamponantes e eletrólitos, altamente relacionados à intensidade fermentativa cecal (Cheeke, 1995). Os teores de fibra em detergente neutro (FDN) e ácido (FDA) foram maiores para os cecotrofos de coelhos alimentados com rações de menor nível de amido (BA), sugerindo um reflexo direto do tipo de alimento ingerido sobre a composição dos cecotrofos, pois a fibra é o substrato de maior representatividade para ação fermentativa pela microflora cecal (De Blas \& Wiseman, 1998). No caso da fonte de fibra, os maiores valores de FDN e FDA nos cecotrofos observados com as rações de feno de alfafa (FA) sugerem que estas variações possuem relação direta com a natureza da fração fibrosa e seus efeitos dentro do trato digestivo, como higroscopicidade, fermentescibilidade, tempo de retenção e taxa de renovação do conteúdo cecal, entre os mais relevantes (Cheeke, 1987; De Blas, 1989; Gidenne, 1996).

Para os teores de proteína e energia dos cecotrofos, pode-se observar na Tabela 4 o efeito da interação entre nível de amido e fonte de fibra, constatando-se que a maior concentração de proteína e energia foi oriunda de cecotrofos de coelhos alimentados com rações de maior nível de amido e casca de soja (AACS), enquanto a menor concentração originou-se de cecotrofos de coelhos alimentados com rações de menor nível de amido e feno de alfafa (AFFA). Isto sugere que a sincronização de fontes de nitrogênio amoniacal e carboidratos altamente fermentáveis no conteúdo cecal dos coelhos alimentados com ração de maior nível de amido e caca de soja (AACS) permitiu maior atividade e desenvolvimento da microbiota, elevando os níveis destes nutrientes nos cecotrofos, tanto pelos produtos do metabolismo quanto pela própria massa microbiana (Fekete \& Bokori, 1985; Gomes, 1996), além do alto valor energético da casca de soja (Garcia et al., 1997).

Para a contribuição nutricional da cecotrofia, constatou-se influência sobre as médias de matéria seca tanto para nível de amido quanto para fonte de fibra $(\mathrm{P}<0,05)$, não houve efeito significativo sobre

R. Bras. Zootec., v.32, n.4, p.891-902, 2003 
proteína, mas em energia houve influência do nível de amido da ração $(\mathrm{P}<0,05)$, além disso, verificou-se influência sobre a contribuição em FDN para nível de amido $(\mathrm{P}<0,05)$ e sobre a contribuição em FDA para nível de amido ou fonte de fibra $(\mathrm{P}<0,05)$, mas não para a interação entre eles. Na Tabela 4 , pode-se observar a melhor contribuição em matéria seca pelos cecotrofos foi obtida com as rações de alto amido (AA) e as rações contendo feno de alfafa (FA), para este último, efeito direto propiciado por maior consumo de alimento, mas atenuado pelo teor de matéria seca dos cecotrofos. A contribuição em proteína bruta pela cecotrofia foi similar entre as rações contendo diferentes fontes de fibra e níveis de amido, porém observa-se leve superioridade com rações de feno de alfafa (FA), devido ao volumoso com maior grau de lignificação e à natureza protéica deste volumoso (Proto, 1976; Carabaño et al., 1988; Fraga et al., 1991; Ferreira et al., 1996; Gomes, 1996).

Para contribuição em energia pelos cecotrofos, nota-se na Tabela 4 que maiores valores foram obtidos com as rações de maior nível de amido (AA), possivelmente relacionado à intensidade fermentativa condicionada pelo tipo de substrato que escapou da digestão intestinal, como mencionado anteriormente para concentração AGV cecal. A fibra reingerida com os cecotrofos, tanto em FDN quanto em FDA, foi maior para rações de menor nível de amido (BA), pois a relação dietética entre amido e fibra foi inversa, aliada à capacidade de separação mecânica de partículas mais digestíveis das menos digestíveis na região do ceco-cólon, pela dualidade na excreção fecal e natureza da fonte de fibra.

Com relação à fonte de fibra dietética, pode-se notar na Tabela 4 que a maior contribuição em matéria seca, em FDN e FDA, foi proporcionada pelas rações contendo feno de alfafa (FA), o que possivelmente se justifica pela natureza da parede celular e sua interação com a fisiologia digestiva peculiar destes animais (Proto, 1984; Carabaño et.al., 1988; Fraga et al., 1991; Maertens, 1992; Ferreira et al., 1996; Gomes, 1996). A quantidade de cecotrofos produzidos, a composição química e sua contribuição nutricional em coelhos podem apresentar grande variabilidade na literatura, devido à categoria animal, ao tempo de coleta, à dieta utilizada e ao uso de um colar para prevenir a cecotrofia, um adicional fator de estresse (Proto, 1976; Cheeke, 1987; De Blas, 1989; Gomes, 1996).

\footnotetext{
R. Bras. Zootec., v.32, n.4, p.891-902, 2003
}

\section{Conclusões}

Os coelhos alimentados com rações contendo maior nível de amido e com as rações contendo casca de soja, apresentaram maior atividade fermentativa e maior enriquecimento nutricional do conteúdo cecal. A contribuição nutricional da cecotrofia foi otimizada nos coelhos alimentados com as rações com maior nível de amido, mas similar para as diferentes fontes de fibra.

\section{Agradecimento}

À Santista Alimentos SA - Divisão SAMRIG, pela doação da casca de soja usada neste estudo.

\section{Literatura Citada}

ASSOCIATION OF OFFICIAL ANALYTICAL CHEMISTS AOAC. Official methods of analysis. 15.ed., Virginia: Arlington, 1990. 1117p.

ARRUDA, A.M.V. Digestibilidade, desempenho e produção de ácidos graxos voláteis de coelhos alimentados com rações contendo diferentes níveis de amido. Jaboticabal: Universidade Estadual Paulista, 1997. 96p. Dissertação (Mestrado em Zootecnia) - Universidade Estadual Paulista, 1997.

ARRUDA, A.M.V.; CARREGAL, R.D.; FERREIRA, R.G. Desempenho produtivo e atividade microbiana cecal de coelhos alimentados com rações contendo diferentes níveis de amido. Revista Brasileira de Zootecnia, v.29, n.3, p.762-768, 2000 .

BELLIER, R.; GIDENNE, T. Consequences of reduced fiber intake on digestion, rate of passage and caecal microbial activity in the young rabbit. British Journal Nutrition, n.75, p.353-363, 1996.

BLAS, E.; FANDOS, J.C.; CERVERA, C. et al. Effet de la nature et du taux d'amidon sur l'utilisation digestive de la ration chez le lapin au cours de la croissance. Paris, 5 émes Journees de la Recherche Cunicole, 1990. 10p. (communication 50)

CARABAÑO, R.; FRAGA, M.J.; SANTOMA, G. et al. Effect of diet on composition of cecal contents and on excretion and composition of soft and hard feces of rabbits. Journal of Animal Science, v.66, n.4, p.901-910, 1988.

CARABAÑO, R.; FRAGA, M.J.; DE BLAS, J.C. Effect of protein source in fibrous diets on performance and digestive parameters of fattening rabbits. Journal of Applied Rabbit Research, v.12, n.3, p.201-204, 1989.

CARABAÑO, R. Sistemas de producción de conejos en condiciones intensivas. In: REUNIÃO ANUAL DA SOCIEDADE BRASILEIRA DE ZOOTECNIA, 37., 2000, Viçosa, MG. Palestras... Viçosa, MG: Sociedade Brasileira de Zootecnia, 2000. p.17-38.

CARREGAL, R.D. Efeito da idade e de diferentes níveis de fibra bruta sobre a digestibilidade de nutrientes de rações de coelhos. Piracicaba: Escola Superior de Agricultura Luiz de Queiroz, 1976. 70p. Dissertação (Mestrado em Zootecnia) Escola Superior de Agricultura Luiz de Queiroz, 1976.

CASTROVILLI, C.R.; GREPPI, G. Recenti acquisizioni sull'alimentazione del coniglio. Rivisti di Coniglicoltura, 
v.27, n.2, p.43-55, 1990.

CHEEKE, P.R.; PATTON, N.M. Carbohydrate-overload of the hindgut: a probable cause of enteritis. Journal of Applied Rabbit Research, v.3, n.1, p.20-23, 1980.

CHEEKE, P.R. Rabbit feeding and nutrition. Oregon: Academic Press, 1987. 380p.

CHEEKE, P.R. Alimentación y nutrición del conejo. Zaragoza: Ed. Acribia, 1995. 429p.

CHURCH, D.C. The ruminant animal digestive physiology and nutrition. New Jersey: Prentice Hall, 1988. 562p.

COMI, G.; CANTONI, C. Flora microbica intestinale del coniglio. Rivisti di Coniglicoltura, v.11, n.9, p.79-81, 1984.

DE BLAS, C. Alimentación del conejo. Madrid: Ed. MundiPrensa, 1989. 175p.

DE BLAS, C. Alimentazione in svezzamento i patologia digestiva. Rivisti di Coniglicoltura, v.28, n.7, p.13-21, 1991.

DE BLAS, C.; WISEMAN, J. The nutrition of the rabbit. Cambridge: University Press - CAB International, 1998. $344 p$.

FEKETE, S.; BOKORI, J. The effect of the fiber and protein level of the ration upon the caecotrophy of rabbit. Journal of Applied Rabbit Research, v.8, n.2, p.68-71, 1985.

FERREIRA, W.M. Matérias-primas utilizadas na formulação de rações para coelhos: restrições e alternativas. Informativo Agropecuário, v.14, n.159, p.16-24, 1989.

FERREIRA, W.M.; FRAGA, M.J.; CARABAÑO, R. Inclusion of grape pomace in substitution for alfalfa hay in diets for growing rabbits. Animal Science, v.63, n.1, p.167-174, 1996.

FORSYTHE, S.J.; PARKER, P.S. Nitrogen metabolism by the microbial flora of the rabbit caecum. Journal of Applied Bacteriology, v.52, n.4, p.363-369, 1985 a.

FORSYTHE, S.J.; PARKER, P.S. Urea turnover and transfer to the digestive tract in the rabbit. British Journal of Nutrition, v.53, n.1, p.183-190, 1985 b.

FRAGA, M.J.; PEREZ DE AYALA, P.; CARABAÑO, R. et al. Effect of type of fiber on the rate of passage and on the contribution of soft faeces to nutrient intake of finishing rabbits. Journal of Animal Science, v.69, n.4, p.1566$1574,1991$.

GARCIA, G.; GALVEZ, J.F.; DE BLAS, J.C. Effect of substitution of sugar beet pulp in diets for finishing rabbits on growth performance and nitrogen efficiency. Journal of Animal Science, v.71, p.1823-1830, 1993.

GARCIA, J.; VILLAMIDE, M.J.; DE BLAS, J.C. Energy, protein and fiber digestibility of soya bean hulls for rabbits. World Rabbit Science, v.5, n.3, p.111-115, 1997.

GIDENNE, T.; SCALABRINI, F.; MARCHAIS, C. Adaptation digestive du lapin a la teneur en constituints pariétaux du régime. Ann. Zootch., v.40, n.2, p.73-84, 1991.

GIDENNE, T.; PEREZ, J.M. Effect of dietary starch origin on digestion in the rabbit: digestibility measurements from weaning to slaughter. Animal Feed Science and Technology, v.42, p.237-247, 1993a.

GIDENNE, T.; PEREZ, J.M. Effect of dietary starch origin on digestion in the rabbit: starch hydrolysis in the small intestine, cell wall degradation and rate of passage measurements. Animal Feed Science and Technology, v.42, p.249-257, $1993 b$.

GIDENNE, T. Apports de fibres et d'amidon : consequences digestives chez le lapin en croissance. In: JORNADA TÉCNICA SOBRE CUNICULTURA, 7., 1995, Barcelona. EXPOAVIGA'95... Barcelona, 1995a. p.805-825.

GIDENNE, T. Effect of fiber level reduction and glico- oligosaccharide addition on the growth performance and caecal fermentation in the growing rabbits. Animal Feed Science Technology, n.56, p.253-263, 1995b.

GIDENNE, T. Nutritional and ontogenic factors affecting rabbit caeco-colic digestive phisiology. In: WORLD RABBIT CONGRESS, 6., 1996, Tolouse. Invited Papers...Tolouse, AFC - INRA, 1996. p.13-28.

GIDENNE, T.; JEHL, N. Replacement of starch by digestible fiber in the feed for growing rabbit: 1. Consequences for digestibility and rate of passage. Animal Feed Science and Technology, n.61, p.183-192, 1996.

GOMES, A.V.C. Utilização de diferentes fontes de fibra na alimentação de coelhos en crescimento. Belo Horizonte, MG: Universidade Federal de Minas Gerais, 1996. 129p. Tese (Doutorado em Zootecnia) - Universidade Federal de Minas Gerais, 1996.

INSTITUT NATIONAL DE LA RECHERCHE AGRONOMIQUE - INRA. L'alimentation des animaux monogatriques: porc, lapin e volailles. Tolouse, Publiè du Ministère Français, 1984. p.77-84.

JEHL, N.; GIDENNE, T. Replacement of starch by digestible fiber in feed for the growing rabbit: 2. Consequences for microbial activity in the caecum and on incidence of digestive disorders. Animal Feed Science and Technology, n.61, p.193-204, 1996.

LANG, J. The nutrition of the commercial rabbit. Part 1 Physiology, digestibility and nutrient requirements. Nutrition Abstract Reviews, CAB International, Serie-B, v.51, n.4, p.197-221, 1981.

LEBAS, F.; COUDERT, P.; ROUVIER, A. et al. El conejo: cria y patologia. Organización de las Nacioenes Unidas para la Agricultura y la Alimentación. Roma, Colecciones FAO, 1986. 278p.

LEBAS, F. Alimentación y funcionamiento digestivo del conejo. Cuniculture, v.16, n.92, p.224-228, 1991.

LEBAS, F. Recomendações alimentares - alimentação dos coelhos. In: INRA Alimentação dos animais monogástricos: suínos, coelhos e aves. São Paulo, Roca Ltda, 2.ed., 1999. p.76-84.

LLEONART, F.R. Tratado de cunicultura. Anatomía y fisiología del aparato digestivo. Barcelona: Real Escuela Oficial y Superior de Avicultura, v.1, p.61-84, 1980.

MAERTENS, L. Rabbit nutrition and feeding - a review of some recent developments. Journal of Applied Rabbit Research, v.15, n.1, p.889-915, 1992.

MAKAR, H.P.S.; SINGH, B. Comparative enzymatic profiles of rabbit caecum and bovine rumen contents. Journal of Applied Rabbit Research, v.10, n.4, p.172-174, 1987.

MARTY, J.; VERNAY, M. Absorption and metabolism of the volatile fatty acids in the hindgut of the rabbit. British Journal of Nutrition, v.51, n.2, p.265-277, 1984.

MORISSE, J.P. L'Alimentation du lapin: composante primordiale de 1'equilebre digestif, rôle des glucides. Reviste Alimentation Animal, n.354, p.635-642, 1982.

MORISSE, J.P. Incidenza delle turbe digestive e delle enteropatie sulla mortalità del coniglio. Rivisti di Coniglicoltura, v.23, n.2, p.28-36, 1986.

NATIONAL RESEARCH COUNCIL - NRC. Nutrients requirements of rabbits. Washington, D.C.: National Academy Press, 1977. 30p.

PACINI, N., ZANCHI, R. , CORTI, M. et al. Microflora ciecale del coniglio e diete proteiche. Rivisti di Coniglicoltura, v.13, n.6, p.39-41, 1986.

R. Bras. Zootec., v.32, n.4, p.891-902, 2003 
PARIGI-BINI, R.; XICCATO, G.; CINETTO, M. Influenza del contenuto di amido alimentare sulla produtivita, sulla digeribilita e sula composizione corporea di conigli in accrescimento. Zoot. Nutr. Animal, v.16, n.1, p.271$282,1990$.

PEETERS, J.E.; ORSENIGO, R.; MAERTENS, L. et al. Influence of two iso-energetic diets (starch vs. fat) on experimental colibacillosis (EPEL) and iota-enterotoxemia in early weaned rabbits. World Rabbit Science, v.1, n.2, p.53-66, 1993.

PEETERS, J.E.; MAERTENS, L.; ORSENIGO, R. et al. Influence of dietary beet pulp on the caecal VFA, experimental colibacillosis and iota-enterotoxaemia in rabbits. Animal Feed Science and Technology, n.51, p.123-139, 1995.

PIMENTEL GOMES, F.P. Curso de estatística experimental. Piracicaba: Escola Superior de Agricultura "Luís de Queiroz", 1987. $467 \mathrm{p}$.

PROTO, V. Fisiologia della nutrizione del coniglio con particolare riguardo alla ciecotrofia. Rivisti di Coniglicoltura, v.13, n. 7, p.15-33, 1976.

PROTO, V. Aspetti applicativi della ciecotrofia nell'allevamento del coniglio. Rivisti di Coniglicoltura, v.21, n.11, p.26-35, 1984.

SANTOMÁ, G.; DE BLAS, J.C.; CARABAÑO, R. et al. Nutrition of rabbits. Madrid: Cyanamid Ibérica SA, 1993. 57p.
SILVA, D.J. Análise de alimentos: métodos químicos e biológicos. Viçosa, MG: Universidade Federal de Viçosa, 1990. $166 \mathrm{p}$.

TORTUERO, F., RIOPEREZ, J., COSIN, C. et al. Effects of dietary fiber sources on volatile fatty acid production, intestinal microflora and mineral balance in rabbits. Animal Feed Science and Technology, v.48, n.1-2 , p.1-14, 1994. UNIVERSIDADE FEDERAL DE VIÇOSA - UFV. SAEG Sistemas de Análises Estatísticas e Genéticas. Versão 7.1. Viçosa, MG. 1997. 150p. (Manual do usuário).

VAN SOEST, P.J.; ROBERTSON, J.B.; LEWIS, B.A. Methods for dietary fiber, neutral detergent fiber, and nonstarch polyssacharides in relation to animal nutrition. Journal of Dairy Science, v.74, n.10, p.3583-3597, 1991.

VERNAY, M. Origin and utilization of volatile fatty acids and lactate in the rabbit: influence of the faecal excretion pattern. British Journal of Nutrition, v.57, p.371-381, 1987.

Recebido em: 21/01/02

Aceito em: 16/09/02 